\title{
Digging Deeper into the Ecology of Subterranean Ants: Diversity and Niche Partitioning across Two Continents
}

\author{
Mickal Houadria * (D) and Florian Menzel (iD \\ Institute of Organismic and Molecular Evolution, Johannes-Gutenberg-University Mainz, \\ Hanns-Dieter-Hüsch-Weg 15, 55128 Mainz, Germany; menzelf@uni-mainz.de \\ * Correspondence: mickal.houadria@free.fr
}

Citation: Houadria, M.; Menzel, F. Digging Deeper into the Ecology of Subterranean Ants: Diversity and Niche Partitioning across Two Continents. Diversity 2021, 13, 53. https://doi.org/10.3390/d13020053

Academic Editors: Alan N. Andersen and Luc Legal

Received: 4 November 2020

Accepted: 26 January 2021

Published: 29 January 2021

Publisher's Note: MDPI stays neutral with regard to jurisdictional claims in published maps and institutional affiliations.

Copyright: (c) 2021 by the authors. Licensee MDPI, Basel, Switzerland. This article is an open access article distributed under the terms and conditions of the Creative Commons Attribution (CC BY) license (https:/ / creativecommons.org/licenses/by/ $4.0 /)$.

\begin{abstract}
Soil fauna is generally understudied compared to above-ground arthropods, and ants are no exception. Here, we compared a primary and a secondary forest each on two continents using four different sampling methods. Winkler sampling, pitfalls, and four types of above- and below-ground baits (dead, crushed insects; melezitose; living termites; living mealworms/grasshoppers) were applied on four plots $(4 \times 4$ grid points) on each site. Although less diverse than Winkler samples and pitfalls, subterranean baits provided a remarkable ant community. Our baiting system provided a large dataset to systematically quantify strata and dietary specialisation in tropical rainforest ants. Compared to above-ground baits, $10-28 \%$ of the species at subterranean baits were overall more common (or unique to) below ground, indicating a fauna that was truly specialised to this stratum. Species turnover was particularly high in the primary forests, both concerning above-ground and subterranean baits and between grid points within a site. This suggests that secondary forests are more impoverished, especially concerning their subterranean fauna. Although subterranean ants rarely displayed specific preferences for a bait type, they were in general more specialised than above-ground ants; this was true for entire communities, but also for the same species if they foraged in both strata.
\end{abstract}

Keywords: soil arthropods; pitfall; bait; turnover; food specialisation; stratification; sampling methods; hypogaeic

\section{Introduction}

From the tip of the leaves in the canopy of a forest, to the epiphytes living on the branches all the way down the bark, the leaf litter, and even within the first metre of soil, ants are present everywhere. Be they above-ground or hypogaeic foragers, ants contribute significantly to ecosystem functions. In addition to being important in trophic functions as predators [1], their digging activity aerates the soil and promotes nutrient cycling [2]. They often display vertical stratification, with many species being specialised in certain microhabitats. Such stratification has been studied mostly above ground to date, with a focus on canopy vs. understory vs. leaf litter dwellers [3-5]. However, we know even less about the subterranean ants that live only a few centimetres away from our feet-within the soil. We adopt the terminology of [6], with 'subterranean' referring to all ants (and baits) from below ground, whereas 'hypogaeic' refers to species that predominantly live and forage below ground, thus excluding above-ground species that might nest in the soil but do not forage there.

A recent study from the Amazon rainforest [7] captured nine hypogaeic species (out of 47) with subterranean baits that could not be sampled using other methods. This demonstrates that conventional ant sampling methods neglect this fauna almost completely [8-10]; this is also because published protocols on recommended sampling methods mostly include above-ground baits, pitfalls, and Winkler sampling [11], which misses out hypogaeic species. However, hypogaeic ant communities include important lineages which could 
shed light on the early development of ancestral ants. They include phylogenetically ancient and conserved ant lineages. For example, the recently discovered Martialis heureka represents the sister lineage to all other ants. It is a hypogaeic ant, with the first two specimen being collected in soil core samples [12]. Within the clade that is sister to Martialis, the blind, hypogaeic subfamily Leptanillinae is sister to all other ant taxa, which implies that cryptobiotic, blind ants evolved and diversified early in ant evolution [12]. Thus, hypogaeic ants may become key to our understanding of the ecology and evolution of early ants. Many specialised and cryptobiotic ant genera, which often include blind species, are collected almost exclusively using subterranean baiting or soil/leaf-litter sampling (such as Anillomyrma, Prionopelta, Simopelta, Leptanilla, and Aenictus) [6]. However, a severe obstacle to research on subterranean ants is that exhaustive and reliable sampling remains challenging.

The difficult sampling also limits our understanding of ecosystem processes in which these ants are involved. For instance, the environmental importance of army ants in tropical ecosystems has been demonstrated through the study of above-ground species such as Eciton [1,13]. However, as the majority of army ant genera are hypogaeic, we probably underestimate the ecological impact of army ants [14]. Here, two important aspects to understand ecological niches are stratification, i.e., the degree of specialisation in subterranean habitats, and dietary specialisation. A good way to determine these is offering different baits [15] in a single grid-point location but on both strata.

Most studies with subterranean baits have used mixtures of processed food resources $[1,8,13,15-17]$. This is a highly effective way to attract the maximum possible range of ants but does not yield information on the dietary specialisation of subterranean ants. Al-though baits that mimic natural resources necessarily sample only a subset of the ant fauna $[16,18]$, they provide valuable information on the dietary preferences of these species [15], which are not only important aspects of their ecology, but will also improve how to sample certain species specifically. On a similar note, it is not known if ants forage on the same food sources above and below ground. For instance, certain ant species that tend aphids above ground could be preying on termites below ground (or vice versa).

Like other cryptobiotic ants, hypogaeic species might be especially sensitive to disturbance [19]. Therefore, it is crucial to analyse the ant diversity of subterranean communities across primary and disturbed habitats. To facilitate conservation efforts, it is also important to know if different strata respond to habitat disturbance in a similar fashion and if this differs between tropical regions.

In this study, we investigated the diversity and ecology of subterranean ants at rainforest sites in the Neotropics and Paleotropics. Using a complex sampling design, with 64 spatial replicates per site, above-ground baits were placed at the identical location to the subterranean baits in order to separate ants that forage in both strata to those unique to one of them. To compare baiting efficiency to more conventional methods, pitfalls and Winkler extractions were also performed in each plot (Figure S1). This standardised design was completed in four tropical rainforest sites, providing an extraordinarily large data base to study the ecology and distribution of subterranean ants. The focal research areas of our study are supported by a recent review on subterranean ants [6], which pointed out a lack of publications in the aspects we have addressed here.

First, we compared subterranean baiting to the other three methods regarding taxonomic yield and complementarity, and identified the species only caught with this method. Second, we compared ant assemblages attracted to aboveground and subterranean baits, and calculated stratum specialisation for each species. Third, we analysed $\alpha$ and $\beta$ diversity above and below ground to determine whether patterns of biodiversity were consistent across sites. Finally, based on the ant communities found at the four different bait types, we analysed trophic specialisation in aboveground and subterranean ant communities. 


\section{Material and Methods}

\subsection{Study Site}

Ant sampling was done in two neotropical and two paleotropical sites in 2012 (French Guiana, France) and 2013 (Sabah, Borneo, Malaysia), respectively. On each continent, we sampled one primary and one secondary forest, henceforth abbreviated 'NPF' (neotropical primary forest), 'PSF' (paleotropical secondary forest), and so on. In the neotropics, the Les Nouragues Nature Reserve was studied as a primary forest $\left(\mathrm{NPF}, 4^{\circ} 05^{\prime} \mathrm{N}, 52^{\circ} 41^{\prime} \mathrm{W}\right.$, $90 \mathrm{~m}$ a.s.1.), which covers $>100,000$ ha of pristine forest. The secondary forest site was a 16-ha forest fragment, bordered by urban grass and surrounded by residential areas on the Campus Agronomique in Kourou (NSF, $5^{\circ} 09^{\prime} \mathrm{N}, 52^{\circ} 39^{\prime} \mathrm{W}, 8 \mathrm{~m}$ a.s.1.). In the paleotropics, primary forest was sampled in the Danum Valley Conservation Area (PPF, Sabah, Malaysian Borneo; $4^{\circ} 55^{\prime} \mathrm{N}, 117^{\circ} 40^{\prime} \mathrm{E}, 296 \mathrm{~m}$ a.s.1.). The site is part of a $438-\mathrm{km}^{2}$ primary forest dominated by Dipterocarpaceae trees. As a secondary forest, the Malua Forest Reserve was chosen (PSF, $4^{\circ} 24^{\prime} \mathrm{N}, 118^{\circ} 14^{\prime} \mathrm{E}, 6 \mathrm{~m}$ a.s.l.). It comprises $35 \mathrm{~km}^{2}$ of production forest, which was selectively logged in the 1980s.

\subsection{Sampling Design}

In each site, we established four plots of $4 \times 4$ grid points each, i.e., a total number of 64 grid points. Within a plot, the distance between grid points was $10 \mathrm{~m}$ (Figure S1); the four plots were separated by at least $150 \mathrm{~m}$. At each grid point, we placed pitfalls, above-ground baits, and subterranean traps. Winkler sampling was conducted for all areas within four grid points, resulting in four Winkler samples per plot and 16 per site (Figure 1). Data from the above-ground baits and pitfalls were partly analysed and published previously [2,15,20-22].
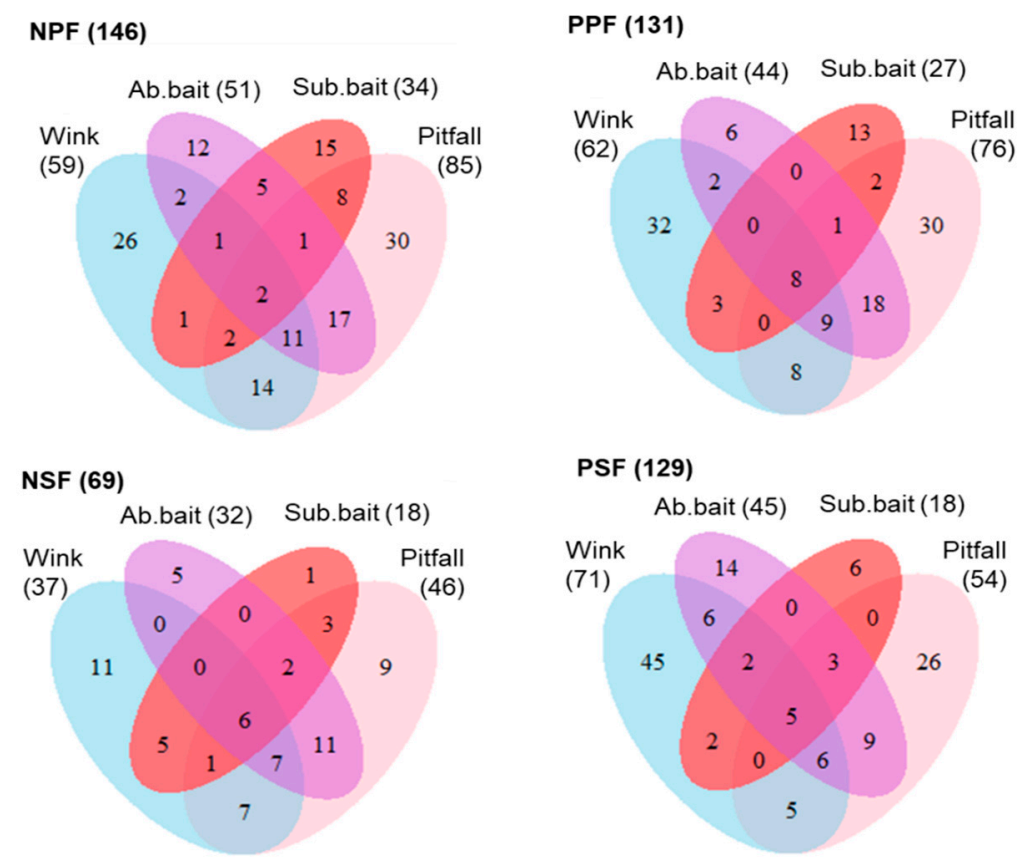

Figure 1. Venn diagrams for each site, comparing the ant species sampled by the four different sampling methods. Wink, Ab.bait, and Sub.bait stand for Winkler samples, above-ground baiting, and subterranean baiting, respectively. The numbers on overlapping sections are the number of species common to the sampling methods concerned, otherwise they are unique to one sampling method. Overall species richness for each method and site is written in brackets.

\subsubsection{Above-Ground Baits}

The baits were presented in small plastic boxes with slits at the sides for 90 min and then quickly retrieved. We presented four bait types that reflected natural resources available to ants in a rainforest: melezitose (reflecting trophobiont honeydew); dead, crushed insects 
(carrion); living termites (small prey); and living grasshoppers (large prey). The four different above- and below-ground baits were separately presented at a given time, i.e., there were never two baits displayed on a grid point simultaneously. Melezitose was presented in a $20 \% \mathrm{~m} / \mathrm{v}$ solution on paper tissue; approx. 10 living termites were kept free on the paper towel and usually stayed on a small piece of humid termite mound which was added. The living grasshopper was tethered to the bait box to prevent escape. At each grid point, all above-ground baits were presented separately during the day (between 10:00 to 15:00) and night (between 20:00 to 23:00). For the present study, the two time periods were pooled per grid point and bait type, in order to be comparable to the subterranean baits left for the whole 24-h cycle. Additional above-ground baits that have been presented but were not considered for this study include sucrose, bird faeces, and seeds [2,15,20-22]. Therefore, numbers of species or occurrences may differ from our previous studies.

\subsubsection{Subterranean Baits}

Subterranean traps consisted of closed Eppendorf cups $(1.5 \mathrm{~mL})$ that contained a food resource. The cups had four holes drilled in the upper half to allow access by ants, as described by Andersen and Brault [10] (see also Figure S1). Based on previous studies $[7,18,23]$, the highest species richness is obtained between 10 and $20 \mathrm{~cm}$ and most species are sampled within a $24 \mathrm{~h}$ timeframe $[7,10]$. Therefore, after litter removal, traps were buried $10 \mathrm{~cm}$ deep into the soil, and carried a wire which stuck out from the soil for quick retrieval. For practical reasons (weather and preparation), one bait type was displayed for $24 \mathrm{~h}$ simultaneously on all 64 grid points within a site. We used the same four baits as above (melezitose, termites, crushed insects), but replaced live grasshoppers by live $1.5-\mathrm{cm}$ mealworms as it seemed more suitable as a large subterranean prey [18]. To present melezitose, a cotton ball was compacted in the concave lids, which was then saturated with $2 \mathrm{~mL}$ of $20 \% \mathrm{~m} / \mathrm{v}$ solution. The crushed insect paste was compressed in a similar way. To keep the mealworms in place and prevent them falling in the killing solution, the mealworm was pinned to the lid using the tip of a needle, minimizing the wound for the mealworm to be still capable of wriggling. For the last bait, three to four termites were glued alive to a $1-\mathrm{cm}$ piece of toothpick which was then inserted through the lid in a similar fashion as the mealworm. Preliminary tests showed that mealworms and termites survive for over $20 \mathrm{~h}$ in this state.

\subsubsection{Pitfalls and Winkler Extractions}

Sampling methods were performed at separate times to avoid interference between them. Pitfalls were left open for $12 \mathrm{~h}$ during the day (6:00-18:00) or night (18:00-6:00); this was done three times consecutively before retrieval. For the present study, day and night pitfall data were pooled for each grid point. Leaf litter was sampled at four places in each plot. We sampled litter and superficial soil from $1 \mathrm{~m}^{2}$ quadrats in the middle of each of the four grid points. Samples were put in Winkler extraction devices for $48 \mathrm{~h}$; ants were collected in an ethylene-glycol solution.

\subsubsection{Species Identification}

All ants were identified to genera using Bolton [24] and using a binocular microscope (Leica S8AP0). Reference collections with voucher specimens of all ant species were prepared. Morphospecies numbers were assigned consecutively in the order of detection in samples. The collections are deposited at the Institute of Organismic and Molecular Evolution, University of Mainz, Germany. Several morphospecies, including the most common ones, were identified to species using specialised literature [25-27] or the help of specialists (Tables S1 and S2). In particular, several Pheidole and Crematogaster species were kindly identified by John Longino and Bonnie Blaimer, respectively. Notably, the identification of taxonomically challenging dimorphic genera such as Pheidole and Carebara is easier with bait samples than with other sampling methods because major and minor workers are often collected together. This way, more conspecific individuals are present, 
especially in the case of bait monopolization, which is helpful especially in order to identify species with dimorphic workers (pers. comm. J. Longino 2013).

\subsection{Statistical Analysis}

\subsubsection{Sampling and Baiting Complementarity}

The exhaustiveness of Winkler samples, both baiting systems (with bait types summed) and pitfalls was estimated by calculating Cole's rarefaction curves. We also estimated the expected species richness with the Chao2 species richness estimator with EstimateS 9.0 [28]. All other statistics were calculated using R version 3.6.2 (R Core Team 2018, Vienna, Austria; https:/ /www.R-project.org/). The complementarity of species captured was visualised using Venn diagrams, $\mathrm{R}$ (VennDiagram, Venneuler packages). For the subsequent analyses, we only considered above-ground and subterranean baiting data, disregarding pitfalls and Winkler samples.

\subsubsection{Diversity Measures above and below Ground}

Species richness per grid point ( $\alpha$ diversity) was calculated including singletons, separately above and below ground. These species numbers were compared using mixedeffects models with species richness as the dependent variable, site and stratum as fixed variables and grid points as random effects. Species turnover ( $\beta$ diversity) was calculated as the proportion of unique species, viz. $(b+c) /(a+b+c)$, with $a$ being the species shared between two grid points, and $b$ and $c$ being the species unique to the two samples of each comparison. For vertical turnover, we compared these values between above-ground and subterranean assemblages of the same grid point. The values were arcsine-square root transformed and compared between sites using linear models (LM); pairwise comparisons were based on model summaries.

Horizontal turnover was calculated as the proportion of unique species in pairwise comparisons between all grid points within the same $4 \times 4$ plot. This was done separately for above-ground and subterranean baits. Horizontal turnover values were then transformed as above and compared between sites and strata using a linear model with stratum and site and their interaction as fixed factors. Models were analysed using Anova (package car) in R.

\subsubsection{Trophic and Strata Specialisation}

Both aboveground and subterranean baits are active sampling methods, which capture only foraging ants that are attracted. Thus, it makes most sense to compare specifically these two sampling methods to assess trophic and strata specialization. Here, we included only species with at least five occurrences at above-ground or subterranean baits. This way, there were enough occurrences that the species might have foraged at all four resources. For strata specialisation, we calculated the number of occurrences above and below ground for each species. These were compared using $\chi^{2}$ tests, followed by correction for false discovery rate.

Next to strata specialisation, food preferences were calculated using a randomization algorithm based on the number of occurrences per bait. A null model randomly swapped occurrences over 1000 permutations; the bait was defined as 'preferred' if realised occurrences were higher than the $95 \%$ confidence interval of the random expectation [15]. This was done separately for both strata.

Furthermore, we assessed the overall degree of food specialisation $(f s)$. A common species is more likely to encounter different food types by chance; therefore we rarefied down to five occurrences and calculated $f s$; this was done 1000 times per species. 'Food specialisation' $f s$ was calculated similarly to Simpson's diversity index as $f_{s}=\Sigma p_{i}{ }^{2}$, where $p_{i}$ is the number of occurrences at bait type $i$ divided by the total number of occurrences for the given species. $f_{s}$ considers the relative specialisation of a species on any resource and ranges from 0 to 1 . In contrast, 'food preferences' provide information about the actual resources that are foraged. A species specialised in one resource will prefer it, but a 
species with several preferences may or may not be highly specialised overall [15]. Food specialisation was calculated separately for above- and below-ground baits and compared using $t$-tests. In a second analysis, we compared food specialisation for only those species which foraged in both strata using a paired $t$-test. Food specialisation of the overall species community was further compared between strata using the $\mathrm{H}_{2^{\prime}}$ index [29] using the $\mathrm{R}$ package bipartite, which ranges from 0 (maximum generalisation) to 1 (maximum specialisation of the entire community).

\section{Results}

\subsection{Species Richness for Different Sampling Techniques and Strata}

Subterranean baits yielded the lowest richness in all four sites (18 in both secondary forests and up to 34 in NPF), but always had between one (PSF) and 15 (NPF) unique species which were not captured with any other method (Figure 1). In contrast, Winkler samples (followed by pitfalls) yielded the highest species numbers, giving between 37 (NSF) and 71 (PSF) species per site (Figure 1). Furthermore, overall expected richness (Chao 2 estimators) was highest for Winkler and pitfall samples compared to the two baiting methods (Figure 2). In above-ground baits, ants were attracted onto 62 to 64 out of 64 grid points per site. In contrast, subterranean baits attracted ants onto only 49 (PPF) to 57 (PSF) out of 64 grid points.

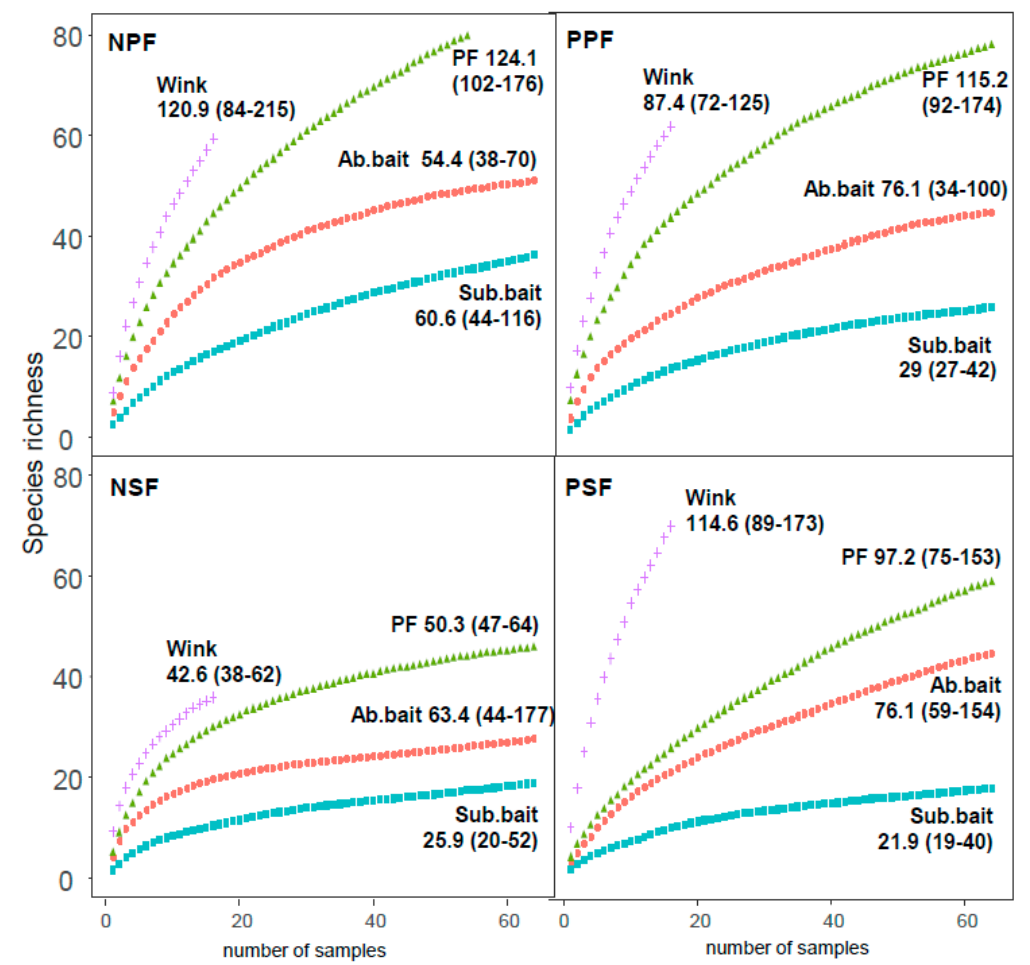

Figure 2. Rarefaction curves for all four different sampling methods. For both subterranean and above-ground baiting, the four different baits were pooled according to grid points before rarefaction. Numbers in bold represent Chao 2 estimates of total species richness for each sampling method, with confidence intervals in brackets. Wink, Ab. bait, Sub.bait, and PF stand for Winkler samples, above-ground baiting, subterranean baiting, and pitfalls, respectively.

Species richness per grid point was always higher above ground than below ground $\left(\mathrm{F}_{1}=418.0, p<0.0001\right.$; Figure $\left.3 \mathrm{~A}\right)$. Above-ground richness differed substantially between sites, whereas below-ground richness did not (site $\times$ stratum interaction: $\mathrm{F}_{3}=12.8$, $p<0.0001 ;$ site: $\left.\mathrm{F}_{3}=13.7, p<0.0001\right)$. 

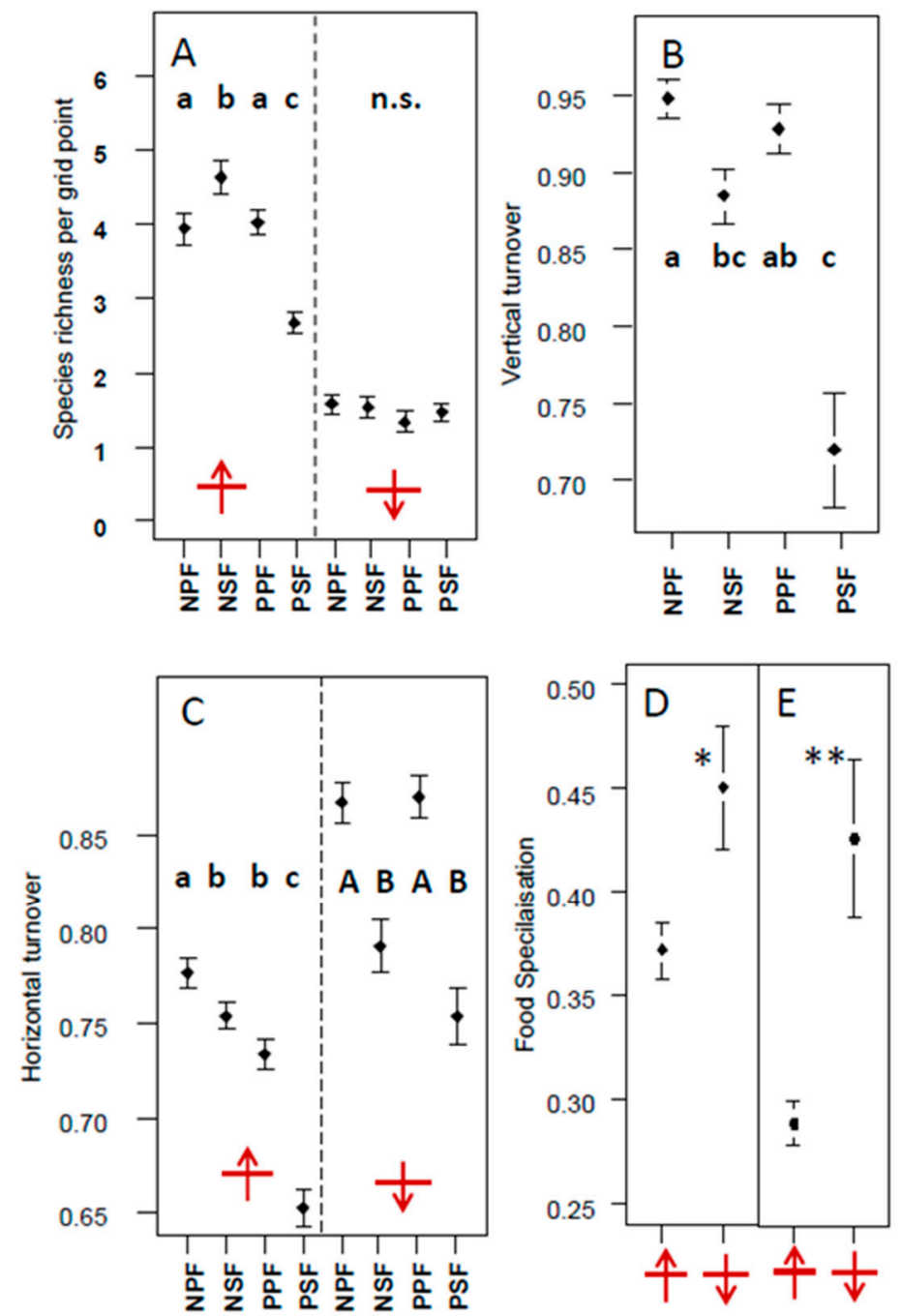

Figure 3. Diversity in above-ground and subterranean baits (arrows pointing up and down, respectively). (A) Species richness per grid point for above-ground and subterranean baiting. (B) Vertical turnover, given as the proportion of species unique to either above-ground or subterranean baits (for each grid point separately). (C) Horizontal turnover, given as the proportion of species unique to a grid point compared to any other grid point of the same $4 \times 4$ plot (separately for above-ground and subterranean baits). Sites with the same letters are not significantly different. (D,E) Species-specific food specialisation $(f s)$ in assemblages above or below ground, with higher values indicating higher specialisation. (D) depicts all species with at least five occurrences; (E) depicts only those species that occurred in both strata with at least five occurrences. Significant differences are denoted with asterisks $\left({ }^{*} p<0.05,{ }^{* *} p<0.01\right)$.

\subsection{Taxonomic Composition and Stratum Specialisation at Different Baits}

Subfamily and genus composition differed between above-ground and subterranean baits. Dolichoderinae were absent from subterranean baits, but occurred above ground in all sites (Figure 4). Among the Formicinae, certain genera were only found above ground (Euprenolepis, Camponotus, Dinomyrmex, Polyrhachis), whereas others were only found in the subterranean baits (Acropyga, Brachymyrmex, Pseudolasius). Only Nylanderia was found in both strata. In the Ectatomminae, Ectatomma was only found in aboveground baits, whereas Gnamptogenys only occurred below ground. Among the Ponerinae, Hypoponera and Parvaponera were exclusive to subterranean baits, whereas Mayaponera, Leptogenys, and Mesoponera were found in both baited strata. Among the Myrmicinae, several genera had species occurring in one or the other strata (Pheidole, Solenopsis, Carebara, Lophomyrmex, Crematogaster), with several remarkable genera exclusive to the subterranean 
strata (Acromyrmex, Hylomyrma, Octostruma, and Epelysidris). In the Dorylinae, Labidus was found in both strata, whereas Dorylus, Aenictus, and Acanthostichus were exclusive to subterranean baits.

In total, $12-28 \%$ of the species per site were significantly more common at subterranean baits than at aboveground baits below ground (considering only species with more than four occurrences, Figure 5). Except for Solenopsis sp. 4 in NPF, all of these species were rare or entirely absent from pitfalls and Winkler samples and thus may be considered truly hypogaeic. Most of these species were Myrmicinae, with only one Ponerinae and three Formicinae species (Table S3). In turn, $60-76 \%$ of the species were more common above ground, and $5-24 \%$ occurred in both strata in similar frequencies.

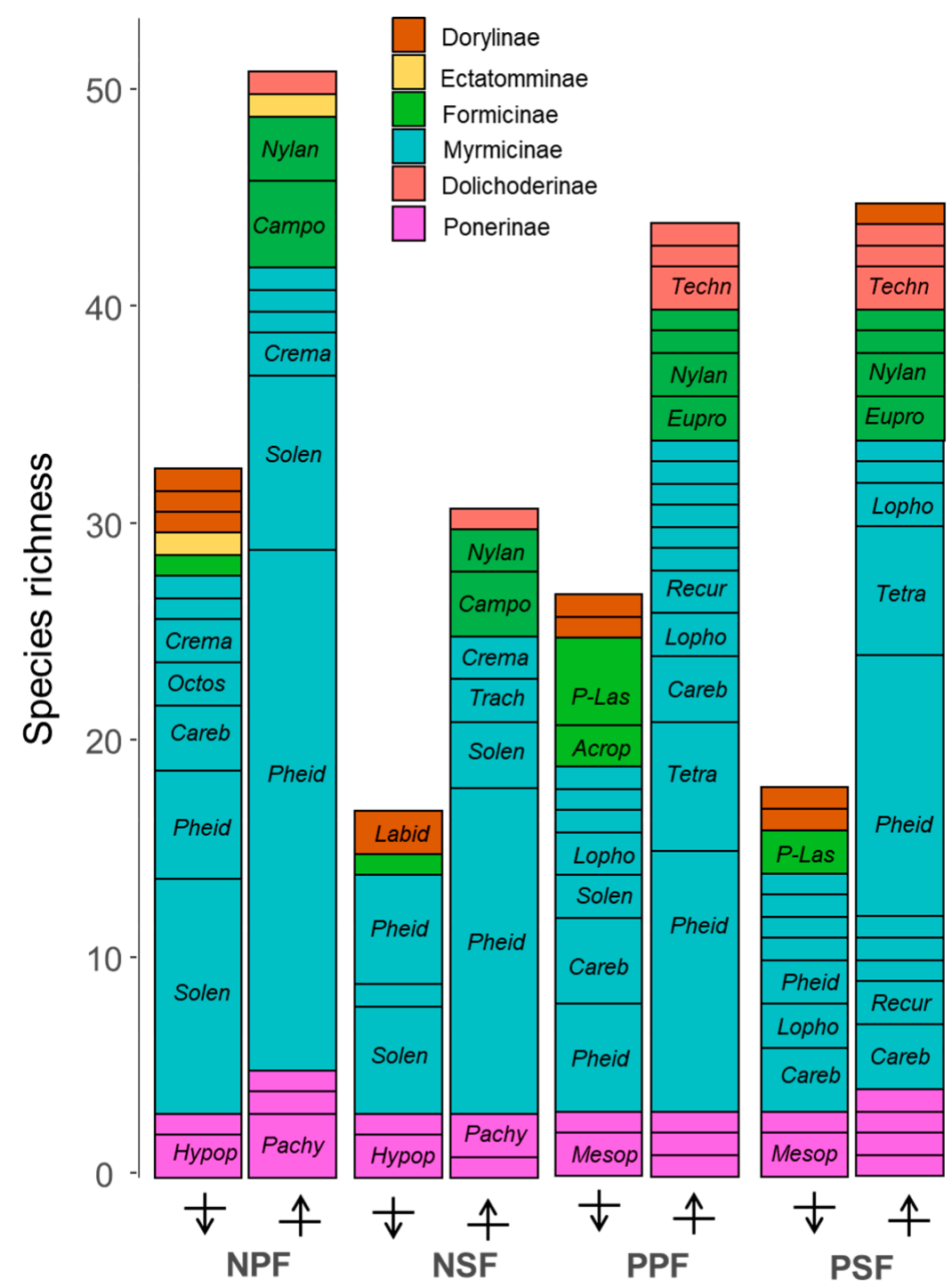

Figure 4. Species richness per subfamily and site for both subterranean and above-ground baiting. Each rectangle represents a different genus, proportional in size to the number of species. Abbreviations are denoted when at least two species were found within the genus. P-Las: Pseudolasius; Acrop: Acropyga; Lopho: Lophomyrmex; Solen: Solenopsis; Careb: Carebara; Mesop: Mesoponera; Techn: Technomyrmex; Hypop: Hypoponera; Nylan: Nylanderia; Eupro: Eupronolepis; Recur: Recurvidris; Tetra: Tetramorium; Pheid: Pheidole; Crema: Crematogaster; Octos: Octostruma; Pachy: Pachycondyla; Campo: Camponotus; Labid: Labidus; Trach: Trachymyrmex. 


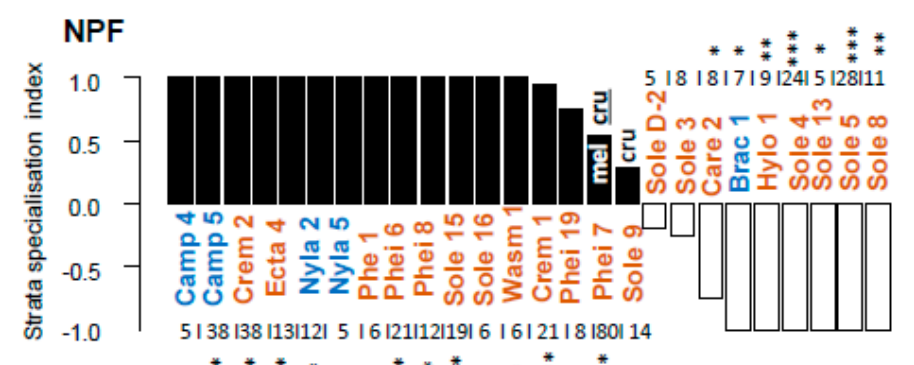

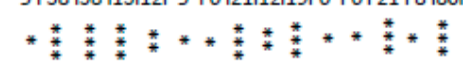
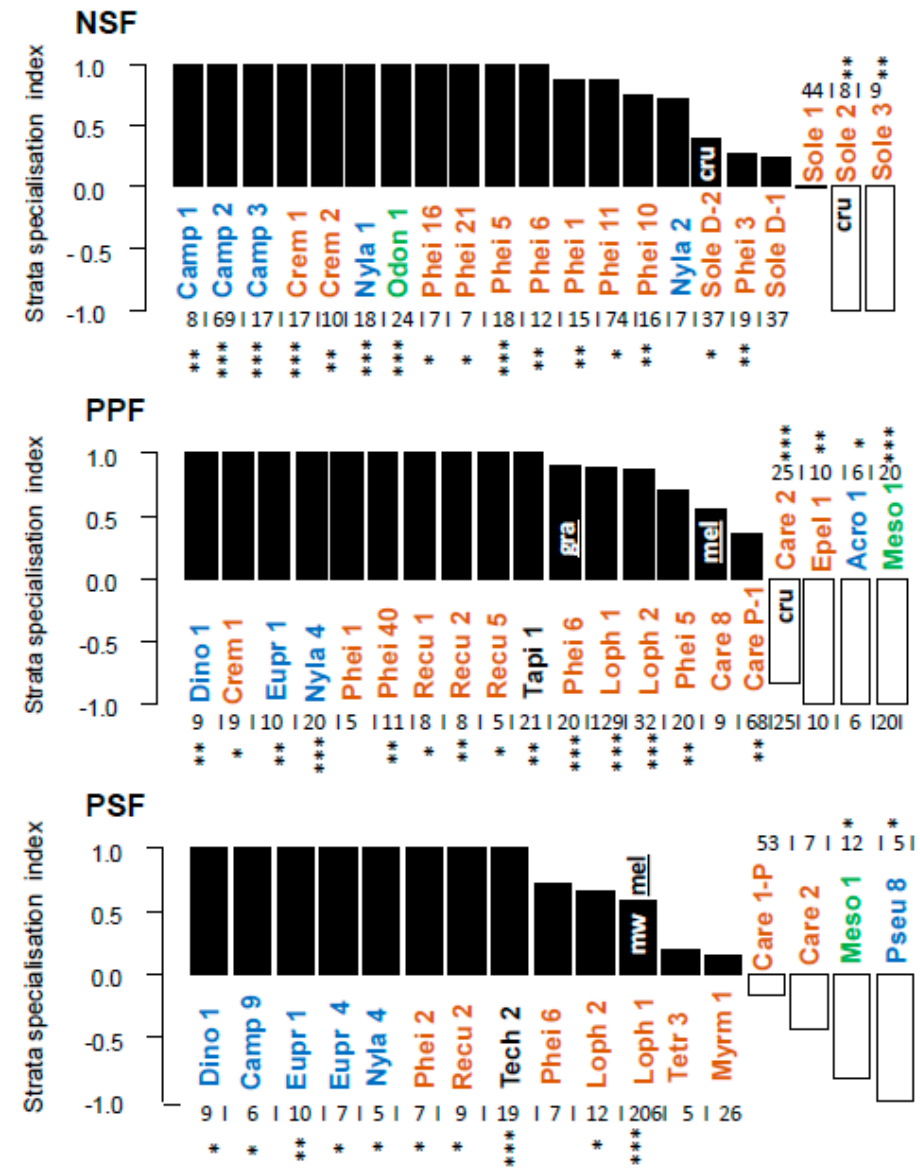

Figure 5. Strata specialisation for each species with five or more occurrences. The values range from 1 (exclusively above-ground) to -1 (exclusively subterranean), based on the number of occurrences. Significant differences between strata $\left(\chi^{2}\right.$ tests) are denoted with asterisks $\left({ }^{*} p<0.05,{ }^{* *} p<0.01\right.$, *** $p<0.001)$; numbers indicate the number of occurrences per strata. Food preferences are denoted when significant: $\mathrm{cru}$, crushed insects, mel: melezitose, gra: grasshopper, mw: mealworm; if the abbreviation is underlined it means the preference was found above ground. Blue, orange, black, and green respectively represent the subfamilies Formicinae, Myrmicinae, Dolichoderinae, and Ponerinae. Genera are abbreviated as follows: Camp: Camponotus, Crem: Crematogaster, Ect: Ectatomma, Nyl: Nylanderia, Phei: Pheidole, Sole: Solenopsis; Wasm: Wasmannia; Care: Carebara, Brac: Brachymyrmex, Hylo: Hylomyrma, Odon: Odontomachus; Dino: Dinomyrmex; Eupr: Euprenolepis; Recu: Recurvidris; Tapi: Tapinoma; Loph: Lophomyrmex; Epel: Epelysidris; Acro: Acropyga, Meso: Mesoponera, Techn: Technomyrmex; Tetr: Tetramorium; Myrm: Myrmicaria. The following morphospecies were identified to species: (neotropical primary forest (NPF) and neotropical secondary forest (NSF)) Camp5: Camponotus femoratus; Crem2: Crematogaster levior; Phei7: Pheidole cf. nitella; Ecta4: Ectatomma tuberculatum; Camp2: Camponotus cf. melanoticus; Crem1: Crematogaster limata; Odon1: Odontomachus haematodus; Phei3: Pheidole subarmata; Phei10: Pheidole zeteki; Phei11: Pheidole pugnax; (paleotropical primary forest (PPF) and paleotropical secondary forest (PSF)) Dino1: Dinomyrmex gigas; Loph1: Lophomyrmex bedoti; Loph2: Lophomyrmex longicornis; Epel1: Epelysidris brocha. See also Tables S1 and S2. 


\subsection{Vertical and Horizontal Turnover}

On both continents, the two secondary forests had a lower vertical species turnover than the two primary forests (LM; factor site: $\mathrm{F}_{3}=18.7, p<0.0001$ ) (Figure 3B). It was lowest in PSF, probably because the two numerically dominant species, Carebara sp.1-Phg (formerly Pheidologeton) and Lophomyrmex bedoti, occurred in both strata in high frequencies (Figure 5). In contrast, the most common species on above-ground baits in NPF (Pheidole cf. nitella, Crematogaster levior, Camponotus femoratus) and NSF (Pheidole subarmata, Pheidole pugnax, Camponotus cf. melanoticus) were all strata specialists, being significantly more common above ground.

Within the same stratum, horizontal turnover between grid points of the same $4 \times 4$ plot ranged from $65 \%$ to $90 \%$ (Figure $3 \mathrm{C}$ ). It was significantly lower above ground $\left(\mathrm{F}_{1}=311.3\right.$, $p<0.0001)$. For both strata, horizontal turnover differed between sites $\left(\mathrm{F}_{3}=40.9, p<0.0001\right)$; this effect was particularly high below ground (site:strata: $F_{3}=7.3, p<0.0001$ ) (Figure 3 C).

\subsection{Dietary Characteristics for Species and Whole Communities}

In both neotropical sites, 'crushed insects' was the most preferred bait with three subterranean and two above-ground species, among which one also preferred melezitose (Figure 5). Melezitose was preferred by one Pheidole species in NPF, one Carebara species in PPF and by Lophomyrmex bedoti in PSF. Concerning the large prey items, mealworms were preferred in subterranean baits only by Lophomyrmex bedoti in PSF, and grasshoppers (above ground) were only preferred by Pheidole sp. 6 in PPF. The different above-ground bait types often yielded additional species in above-ground baits, but this was not always the case for the hypogaeic baits (Figure S2). In general, food specialisation was higher belowground than above-ground. This was evident from species-specific $f_{s}$ values calculated for all species with at least five occurrences above or below ground ( $t$-test: $\mathrm{t}_{41.8}=2.42$, $p=0.020$, Figure 3D), but also when we only considered species found in both strata (paired $t$-test: $\mathrm{t}_{11}=3.30, p=0.0071$, Figure $3 \mathrm{E}$ ). Moreover, below-ground communities were more specialised for all sites except NSF, as indicated by the $\mathrm{H}_{2}$ ' index. For NPF, PPF, and PSF, it ranged from 0.070 to 0.092 above ground and from 0.19 to 0.32 below ground, whereas these values were 0.064 and 0.060 for NSF, respectively.

\section{Discussion}

Although less diverse than the three other sampling methods used in this study, subterranean baiting provided a remarkable ant community in itself (see Text S1 for a comparison of all sampling methods). In each site, $12-20 \%$ of the species were significantly more common below ground or even confined to this stratum (Figure 3). For these species, we were able to assess food preferences and to demonstrate trophic differences depending on whether they were foraging above ground or underground.

\subsection{Species Richness in Above-Ground and Subterranean Baits}

Richness was always lower below ground for all four sites. This aspect was consistent at the grid point level ( $\alpha$ diversity), the plot level (data not shown), and the site level (Chao 2 estimators, Figure 2). However, these results are in accord with only one of the few studies [30] that have performed above- and below-ground baiting. Only in the exceptionally rich NPF, Chao 2 estimates were higher for subterranean than for aboveground baits. This would be more consistent with a previous study, which found that depending on the habitat, the hypogaeic species richness could equal that of above-ground baits [31]. From a taxonomical perspective, all subterranean ant studies are useful in providing valuable geographical and methodological information on this still mostlyunknown stratum. However, in terms of comparing ecological aspects and stratification, we believe that having subterranean baits over a 24-h cycle-compared to baited cards only presented during day time-neglects the numbers of above-ground nocturnal ants which could also come to baits [21]. This could potentially explain why these studies [30,31] found lower species richness differences between above-ground and hypogaeic ant species. One 
study [32] found that honey baits attracted fewer species below ground, but sardine baits attracted similar amounts below and above ground. Our two comparable baits would be melezitose and crushed insects, as sources of carbohydrates and protein, respectively, for which we consistently found lower occurrences in the subterranean strata.

\subsection{Taxonomic Composition above and below Ground}

Subfamilies and genera differed in their occupancy of the two strata. For instance, Dolichoderinae were never found below ground in any site, although they were present on the above-ground baits. To our knowledge, this is consistent with only one study [30]. In other studies, mainly from South and Central America, Linepithema, Azteca, and Dorymyrmex were uncommon but occasionally present in subterranean baits [31-35]. In the Ponerinae, Hypoponera was only sampled in subterranean baits, although only half of the mentioned studies found this rather common genus. To our knowledge, Parvaponera has never been sampled using hypogaeic baiting. Within the Dorylinae, an interesting discovery was Dorylus, which has never been baited except in traditional oil soil soaking [14,36,37]; all other Dorylinae genera were reported previously in at least one other study. Among the Myrmicinae, several genera have never been reported before from subterranean baits, such as Acromyrmex, Hylomyrma, and Epelysidris. This is also the only subfamily in which multiple species (13) occurred often enough in both strata to analyse dietary preferences and specialisation. In the Formicinae, Brachymyrmex was regularly found in subterranean baits, except for in two studies [30,31]. Nylanderia was found frequently in only one other study [34]. To our knowledge, two other genera common in our subterranean baits, Acropyga and Pseudolasius, have never been reported from subterranean baits before. Finally, the genus Camponotus was absent from our subterranean samples, as expected from their ecology. Other studies found Camponotus below ground [30,33,35], but the rare occurrence of these and other usually above-ground ants could also be due to contamination [10,34]. For instance, poor compaction of the soil covering the subterranean bait may facilitate access for above-ground fauna (MH pers. obs.). Although our subterranean sampling was thorough (1024 baits per site), certain subfamilies which we were expecting [6,38], such as the Amblyoponinae (Prionopelta) and Leptanillinae (Leptanilla), even when present in pitfalls and Winkler samples in NSF, were absent from our subterranean samples. Potentially, the baits used were not potent enough in smell (compared to sardine baits) or were simply not adapted to these species' diets (geophilomorph centipedes [6]). Note that although some species of Pseudolasius, Gnamptogenys and Acromyrmex were recorded only in subterranean baits here, these genera are generally not hypogaeic.

\subsection{Vertical and Horizontal Turnover}

Although more species were above-ground specialists than subterranean specialists, $12-20 \%$ of all species found at baits were subterranean specialists, which is similar to a recent study [34]. Thus, subterranean ants represent a community of their own. In addition to the higher horizontal turnover, both primary forests also had a higher vertical species turnover, i.e., more species were unique to each stratum. Moreover, both primary forests had more hypogaeic specialist species (with at least five occurrences) than the secondary forests. Above ground, grid points shared more species than below ground (lower horizontal species turnover), which confirms an earlier study reporting high local turnover among subterranean ants [39]. Possibly, hypogaeic species are more limited in foraging distance or in the ways they detect food resources [1]. This might explain a finer-grained community, and thus a higher horizontal species turnover below ground. Furthermore, in both strata and tropical regions, horizontal species turnover was lowest in the secondary forests. This scales up to a lower richness of subterranean ants on a site level for secondary forests, as suggested by Chao 2 estimates.

The higher diversity in primary forests suggests that hypogaeic ants, like other cryptobiotic species, are particularly vulnerable to disturbance [19]. This explains their lower species richness, but also their lower spatial turnover (horizontal and vertical) in secondary 
forests. This effect was consistent across the two tropical regions, although it is notable that the neotropics were more diverse in our study, and at the site level the two paleotropical sites were similar in species richness. However, considerably more studies are required before any global assertions can be confirmed statistically.

\subsection{Dietary Preferences and Food Specialisation}

Subterranean communities were more specialised than above-ground assemblages, demonstrating that they show a higher degree of specificity in what they forage for. Notably, crushed insects were the most preferred resource in both tropical regions and both strata. This was even more pronounced below ground, where crushed insect was the only preferred bait. This makes sense as nitrogen is among the most limited resources in tropical ecosystems [40]. Interestingly, Pheidole sp. 7 (cf. nitella) in NPF preferred crushed insects in the above-ground strata and melezitose in the subterranean strata; in PSF Lophomyrmex sp.1 (L. bedotti) preferred melezitose above ground and mealworms in subterranean baits. This supports the idea that certain species may display niche variation depending on the ecological context $[2,41]$. Based on the ecology of certain subterranean species, we were expecting melezitose to be preferred by species which tend subterranean mealybugs, such as Pseudolasius and Acropyga [42]. However, it would make also sense that these species are not limited in carbohydrates as they tend coccids in their own nests and rather go foraging for complementary resources. Interestingly, some unexpected species were found foraging melezitose, such as Labidus sp. 2, an army ant that had two out of three occurrences on melezitose, and Mesoponera sp. 1, a ponerine, was found eight times out of 33 on melezitose. Based on their taxonomy and morphology, these species would be considered specialised predators [43], but their foraging of melezitose suggests otherwise. This calls into question the categorization of trophic traits based on morphological criteria [44]. Concerning predation, more ants were found at mealworms than at grasshoppers, but in most cases this involved species which seemed to be more opportunistic than specialised predators (Pheidole and Lophomyrmex). We believe that the partial immobilization of the prey in the subterranean Eppendorf and baited boxes did not always prevent smaller opportunist ants from foraging them (M.H pers. obs.). This, however, does not explain why no ants were found to prefer termites, although termites should be an important prey for hypogaeic tropical ants [45].

\section{Conclusions and Outlook}

Our study showed that subterranean baits provide a reliable means of investigating hypogaeic and other ant species, which are less frequently (or not at all) sampled by pitfalls, above-ground baits, and Winkler sampling. By parallel sampling with multiple baits above and below ground, which has rarely been done before, we assessed strata and trophic specialisation in the subterranean ants, and showed that species were more specialised below ground. Moreover, species widely considered to be specialist predators were actually more generalist. This highlights the fact that the ecology of subterranean ants is still largely unknown and awaits further study, particularly in terms of foraging ecology. For example, in a habitat where smell should be a prevalent feature of food detection (instead of eyesight), we were not expecting a non-odorous sugary bait to be as attractive as strongly smelling baits such as decaying insects. More research on vertical stratification within the soil is urgently needed in order to understand underground food webs especially since subterranean habitats are among the highly threatened, but least studied ecosystems [46].

On a community level, we showed that species turnover between above-ground and subterranean strata was considerably higher in primary forests, regardless of the tropical region. Together with our data on horizontal species turnover, this tentatively suggests that the subterranean ant fauna community may vary more between primary and secondary forests than the above ground community. Hence, subterranean ant communities might be more sensitive to the ecological state of a forest. Especially given the lower time effort 
needed, subterranean baits should hence become part of standard sampling protocols that aim for complete inventories. A further research avenue concerns temporal asynchrony within this little-known community, i.e., whether circadian rhythms affect ant communities in a stratum with no light.

Supplementary Materials: The following materials are available online at https:/ / www.mdpi.com/1424 -2818/13/2/53/s1, Figure S1: The four different sampling methods used; Figure S2: Venn Diagrams comparing the ant species attracted to the four different baits. Table S1: Ant species from NPF and NSF; Table S2: Ant species from PPF and PSF; Table S3: Hypogaeic species. Text S1: Comparing Sampling Methods.

Author Contributions: Conceptualization and methodology: F.M. and M.H.; field work and species identification: M.H.; statistical analysis and writing: M.H. and F.M.; funding acquisition: F.M. All authors have read and agreed to the published version of the manuscript.

Funding: This research was funded by the German Research Foundation (DFG), grant numbers ME 3842/1-1 and 3842/6-1.

Institutional Review Board Statement: Not applicable.

Informed Consent Statement: Not applicable.

Data Availability Statement: All data are available from the authors upon request.

Acknowledgments: We thank the Sabah Biodiversity Council (SaBC), Danum Valley Management Committee (DVMC), and Southeast Asian Rainforest Research Programme (SEARRP) for research permissions in Danum and Malua. In particular, Glen Reynolds (Danum) and our collaborator Arthur Y.C. Chung (FRC, Sandakan) were of great help. In addition to this, thanks to the great Danum and Malua staff for making our stay a pleasurable experience. Furthermore, we thank Jérôme Chave for permission to work at Les Nouragues, and Jérôme Orivel for help in Kourou. Thanks also to Heike Stypa for the whole field work logistics and Mona-Isabel Schmitt, Johanna Arndt, and Eric Schneider for help in the field, and to Jack Longino and Bonnie Blaimer for help with ant identification. This research was made possible by the grants ME 3842/1-1 and ME 3842/6-1 of the Deutsche Forschungsgemeinschaft (DFG).

Conflicts of Interest: The authors declare no conflict of interest.

\section{References}

1. Berghoff, S.; Weissflog, A.; Linsenmair, K.E.; Hashim, R.; Maschwitz, U. Foraging of a hypogaeic army ant: A long neglected majority. Insectes Sociaux 2002, 49, 133-141. [CrossRef]

2. Houadria, M.; Menzel, F. Temporal and dietary niche is context-dependent in tropical ants. Ecol. Entomol. 2020, 45. [CrossRef]

3. Tanaka, H.O.; Yamane, S.; Itioka, T. Within-tree distribution of nest sites and foraging areas of ants on canopy trees in a tropical rainforest in Borneo. Popul. Ecol. 2010, 52, 147-157. [CrossRef]

4. Floren, A.; Biun, A.; Linsenmair, K.E. Arboreal ants as key predators in tropical lowland rainforest trees. Oecologia 2002, 131, 137-144. [CrossRef] [PubMed]

5. Bruhl, C.A.; Gunsalam, G.; Linsenmair, K.E. Stratification of ants (Hymenoptera, Formicidae) in a primary rain forest in Sabah, Borneo. J. Trop. Ecol. 1998, 14, 285-297. [CrossRef]

6. Wong, M.K.L.; Guénard, B. Subterranean ants: Summary and perspectives on field sampling methods, with notes on diversity and ecology (Hymenoptera: Formicidae). Myrmecol. News 2017, 25, 1-16.

7. $\quad$ Ryder Wilkie, K.T.; Mertl, A.L.; Traniello, J.F.A. Biodiversity below ground: Probing the subterranean ant fauna of Amazonia. Naturwissenschaften 2007, 94, 725-731. [CrossRef]

8. Longino, J.T.; Colwell, R.K. Biodiversity assessment using structured inventory: Capturing the ant fauna of a tropical rain forest. Ecol. Appl. 1997, 7, 1263-1277. [CrossRef]

9. Agosti, D.; Alonso, L. The ALL Protocol. In Ants: Standard Methods for Measuring and Monitoring Biodiversity; Agosti, D., Majer, J., Alonso, E., Schultz, T., Eds.; Smithsonian Institution Press: Washington, DC, USA, 2000; p. 280, ISBN 1-56098-858-4.

10. Andersen, A.N.; Brault, A. Exploring a new biodiversity frontier: Subterranean ants in northern Australia. Biodivers. Conserv. 2010, 19, 2741-2750. [CrossRef]

11. Agosti, D.; Majer, J.D.; Alonso, L.E.; Schultz, T.R. Standard Methods for Measuring and Monitoring Biodiversity, 2000th ed.; Duke, J., Ed.; Smithsonian Institution Press: Washington, DC, USA, 2000; Volume 233, ISBN 1560988584.

12. Rabeling, C.; Brown, J.M.; Verhaagh, M. Newly discovered sister lineage sheds light on early ant evolution. Proc. Natl. Acad. Sci. USA 2008, 105, 14913-14917. [CrossRef]

13. Brown, B.; Feener, D.H.J. Parasitic phorid flies (diptera: Phoridae) associated with army ants (hymenoptera: Formicidae: Ecitoninae, dorylinae) and their conservation biology. Biotropica 1998, 30, 482-487. [CrossRef] 
14. Berghoff, S.; Maschwitz, U.; Linsenmair, K.E. Influence of the hypogaeic army ant Dorylus (Dichthadia) laevigatus on tropical arthropod Communities. Int. Assoc. Ecol. 2003, 135, 149-157. [CrossRef] [PubMed]

15. Houadria, M.; Salas-Lopez, A.; Orivel, J.; Blüthgen, N.; Menzel, F. Dietary and temporal niche differentiation in tropical ants-Can they explain local ant coexistence? Biotropica 2015, 47, 208-217. [CrossRef]

16. Fowler, H.G.; Delabie, J.H.C. Resource partitioning among epigaeic and hypogaeic ants (Hymenoptera: Formicidae) of a Brazilian cocoa plantation. Ecol. Austral. 1995, 5, 117-124.

17. Díaz, J.A.; Cabezas-Díaz, S. Seasonal variation in the contribution of different behavioural mechanisms to lizard thermoregulation. Funct. Ecol. 2004, 18, 867-875. [CrossRef]

18. Yamaguchi, T.; Hasegawa, M. An experiment on ant predation in soil using a new bait trap method. Ecol. Res. 1996, 11, 11-16. [CrossRef]

19. Andersen, A.N.; Penman, T.D.; Debas, N.; Houadria, M. Ant community responses to experimental fire and logging in a eucalypt forest of south-eastern Australia. For. Ecol. Manag. 2009, 258, 188-197. [CrossRef]

20. Houadria, M.; Menzel, F. What determines the importance of a species for ecosystem processes? Insights from tropical ant assemblages. Oecologia 2017, 184. [CrossRef]

21. Houadria, M.; Blüthgen, N.; Salas-Lopez, A.; Schmitt, M.I.; Arndt, J.; Schneider, E.; Orivel, J.; Menzel, F. The relation between circadian asynchrony, functional redundancy, and trophic performance in tropical ant communities. Ecology 2016, 97, 225-235. [CrossRef]

22. Grevé, M.E.; Houadria, M.; Andersen, A.N.; Menzel, F. Niche differentiation in rainforest ant communities across three continents. Ecol. Evol. 2019, 1-15. [CrossRef]

23. Eguchi, K.; Bui, T.V. Exploration of subterranean ant fauna by underground bait-trapping-A case study in Binh Chau-Phuoc Buu Nature Reserve, Vietnam (Insecta: Hymenoptera: Formicidae). ARI 2009, 32, $20-24$.

24. Bolton, B. Identification Guide to the Ant Genera of the World; Harvard University Press: Cambridge, MA, USA, 1997; ISBN 0-674-44280-6.

25. Schmidt, C.; Shattuck, S. The higher classification of the ant subfamily Ponerinae (Hymenoptera: Formicidae), with a review of ponerine ecology and behavior. Zootaxa 2014, 3817, 1-242. [CrossRef] [PubMed]

26. Fayle, T.M. Key to the Workers of the 100 Ant Genera and 12 Ant Subfamilies of Borneo in English and Malay. Available online: http:/ / www.tomfayle.com/Key\%20to\%20the\%20ant\%20genera\%20of\%20Borneo\%20v1\%20(English-Malay).pdf (accessed on 21 October 2020).

27. Rigato, F. Revision of the myrmicine ant genus Lophomyrmex, with a review of its taxonomic position (Hymenoptera: Formicidae). Syst. Entomol. 1994, 19, 47-60. [CrossRef]

28. Colwell, R.K. EstimateS: Statistical Estimation of Species Richness and Shared Species from Samples, Version 9; User's Guide and application; Department of Ecology \& Evolutionary Biology, University of Connecticut: Storrs, CT, USA, 2013; Available online: http:/ / purl.oclc.org/estimates (accessed on 1 April 2020).

29. Blüthgen, N.; Menzel, F.; Blüthgen, N. Measuring specialization in species interaction networks. BMC Ecol. 2006, 67, 9.

30. Ryder Wilkie, K.T.; Mertl, A.L.; Traniello, J.F.A. Species diversity and distribution patterns of the ants of Amazonian ecuador. PLOS ONE 2010, 5. [CrossRef]

31. Schmidt, F.A.; Diehl, E. What is the effect of soil use on ant communities? Neotrop. Entomol. 2008, 37, 381-388. [CrossRef]

32. De Souza, D.R.; Stingel, E.; De Almeida, L.C.; Lazarini, M.A.; Munhae, C.D.B.; Bueno, O.C.; Archangelo, C.R.; Morini, M.S.D.C. Field methods for the study of ants in sugarcane plantations in Southeastern Brazil. Sci. Agric. 2010, 67, 651-657. [CrossRef]

33. Schmidt, F.A.; Solar, R.R.C. Hypogaeic pitfall traps: Methodological advances and remarks to improve the sampling of a hidden ant fauna. Insectes Sociaux 2010, 57, 261-266. [CrossRef]

34. Torres, M.T.; Souza, J.L.P.; Baccaro, F.B. Distribution of epigeic and hypogeic ants (Hymenoptera: Formicidae) in ombrophilous forests in the Brazilian Amazon. Sociobiology 2020, 67, 186-200. [CrossRef]

35. Pacheco, R.; Vasconcelos, H.L. Subterranean pitfall traps: Is it worth including them in your ant sampling protocol? Psyche (London) 2012, 2012, 20-23. [CrossRef]

36. Sheikh, A.H.; Ganaie, G.A.; Thomas, M.; Bhandari, R.; Rather, Y.A. Ant pitfall trap sampling: An overview. J. Entomol. Res. 2018, 42, 421-436. [CrossRef]

37. Weissflog, A.; Sternheim, E.; Dorow, W.H.O.; Berghoff, S.; Maschwitz, U. How to study subterranean army ants: A novel method for locating and monitoring field populations of the South East Asian army ant Dorylus (Dichthadia) laevigatus Smith, 1857 (Formicidae, Dorylinae) with observations on their ecology. Insectes Sociaux 2000, 47, 317-324. [CrossRef]

38. Wong, M.K.L.; Guénard, B. Leptanilla hypodracos sp. n., a new species of the cryptic ant genus Leptanilla (Hymenoptera, Formicidae) from Singapore, with new distribution data and an updated key to Oriental Leptanilla species. Zookeys 2016, 551, 129-144. [CrossRef]

39. Jacquemin, J.; Drouet, T.; Delsinne, T.; Roisin, Y.; Leponce, M. Soil properties only weakly affect subterranean ant distribution at small spatial scales. Appl. Soil Ecol. 2012, 62, 163-169. [CrossRef]

40. Davidson, D.W. Resource discovery versus resource domination in ants: A functional mechanism for breaking the trade-off. Ecol. Entomol. 1998, 484-490. [CrossRef]

41. Wong, M.K.L.; Guénard, B.; Lewis, O.T. Trait-based ecology of terrestrial arthropods. Biol. Rev. 2019, 94, 999-1022. [CrossRef]

42. Delabie, J.H.C. Trophobiosis between Formicidae and Hemiptera (Sternorrhyncha and Auchenorrhyncha): An Overview. Neotrop. Entomol. 2001, 30, 501-516. [CrossRef] 
43. Rogerio, R.S.; Brandao, C.R.F. Morphological patterns and community organization in leaf-litter ant assemblages. Ecol. Monogr. 2010, 80, 107-124.

44. Gibb, H.; Stoklosa, J.; Warton, D.I.; Brown, A.M.; Andrew, N.R.; Cunningham, S.A. Does morphology predict trophic position and habitat use of ant species and assemblages? Oecologia 2015, 177, 519-531. [CrossRef]

45. Tuma, J.; Eggleton, P.; Fayle, T.M. Ant-termite interactions: An important but under-explored ecological linkage. Biol. Rev. 2019, 95. [CrossRef]

46. Mammola, S.; Cardoso, P.; Culver, D.C.; Deharveng, L.; Ferreira, R.L.; Fišer, C.; Galassi, D.M.P.; Griebler, C.; Halse, S.; Humphreys, W.F.; et al. Scientists' warning on the conservation of subterranean ecosystems. Bioscience 2019, 69, 641-650. [CrossRef] 